\title{
Fertility Mediating Factors in Sub-Saharan Africa (SSA): Macro-Level Cross Sectional Perspectives
}

\author{
Hadgu Bariagaber ${ }^{a}$
}

\begin{abstract}
The aim of this paper is to investigate the mediating factors of fertility levels and trends in Sub-Saharan African (SSA) countries. The major sources of data of the study are the 2001 and 2002 UNDP (United Nations Development Program), covering 42 SSA countries. The selected antecedent variables of fertility levels and trends include: GDP per capita; female adult literacy rate; infant mortality rate; contraceptive prevalence rate; breastfeeding; access to health services; undernutrition; and level of urbanization. The main analytical techniques of the study include simple central tendency descriptive statistics and advanced multiple regression models. The outputs of the correlation matrix and regression models are shown to influence the levels and trends of fertility positively or negatively, increasing or decreasing fertility levels among the countries. But, contraceptive prevalence level appears to be relatively powerful at $5 \%$ significance level, relatively more decline with the level of urbanization and positively related with poverty level, which cumulatively gives rise to 5.9 total fertility rate per woman. Accordingly, with declining mortality and high fertility level, the era of rapid population growth in SSA countries has not yet been over with all its implications on sustainable development.
\end{abstract}

\section{Keywords}

Fertility, covariates, correlation, central tendency, matrix, multiple regression

Sub-Saharan Africa (SSA) has been experiencing typically progressive and expansive population structure which has been characterised by mortality-dominated decline relative to fertility levels and trends. The relative decline in mortality could be explained by some efforts for reducing tropical diseases and relative improvement in food production. Accordingly, the resultant of moderately declining mortality and persistently high fertility in SSA produced youthful population, which has manifested a broad-based age/sex pyramidal structure.

In the same vein, the population of SSA had been estimated to jump from about 181 million at a growth rate of $2.2 \%$ per annum in 1950 to 621.9 million in
1999 at a rate of $2.8 \%$, which resulted to reach about 806 million by the end of 2000 and was estimated to reach 926 million by the year 2013 (World Population Data Sheet 2013).

The current biological and behavioural mediating factors of fertility in SSA would remain strong in favour of maintaining high birth rates (Zaba and Gregson 1998). In fact, during 1995-2000, the total

aUniversity of Botswana, Botswana

\section{Correspondent Author:}

Hadgu Bariagaber, Department of Population Studies, University of Botswana, P/Bag UB 00705, Gaborone, Botswana 
fertility level for SSA stood at 5.7 children per woman as against 3.5 for less developing countries and 1.6 for industrialised societies [ECA (Economic Eommission for Africa) 1995].

This paper is expected to fill the gap in fertility mediating factors and test the application of analytical models to macro-level data of countries. The main objectives are to examine the differentials of demographic and socio-economic status among the SSA countries; to investigate the extent of the impact of the background and proximate variables on fertility levels; and to foresee the prospects of fertility status in SSA countries.

The future does not totally seem too gloomy to exhibit progress toward the fertility transition. Some countries of the SADC (Southern African Development Community) members such as Botswana, Zimbabwe, and South Africa, etc. have already manifested some decline (Gaisie 1996). For example, the fertility level of Southern African sub region appeared to decline from 6.5 in the 1960 s to about 4.1 in the year 2000 as against from 6.7 to 6.4 for East Africa and West Africa, and from 5.9 to 5.7 for middle Africa [ECA (Economic Eommission for Africa) 1995].

However, the superiority of fertility force over mortality levels in SSA implies that the demographic transition, which had been experienced in Western Europe and tending to experience in the majority of the Asian and Latin American countries, has a long way to go, and the era of rapid population growth would continue for some years to come.

Thus, against the preceding brief introduction, this paper attempts to analyse the demographic and socio-economic fertility mediating factors across the SSA countries.

\section{LITERATURE REVIEW}

The factors which maintained constantly high fertility level in SSA are cumulative effects of all sorts of poverty (education, nutrition, health, socio-cultural practices, etc.). The proximate determinants of fertility have been the motivating or demotivating factors to have depressant effects on fertility levels patterns and trends. Early age at marriage and childbearing is almost universal in rural agricultural environment where we have high illiteracy rates accompanied by low contraceptive prevalence, and infant mortality has still been high which motivates high fertility-compensating effect. The age pattern of fertility has been characterised by early age childbearing (till the end of menopausal period) and too many births, with high desire for family size, ranging from about six children for Ghana to as high as 8.8 in Mauritania in the early 1990's [ECA (Economic Eommission for Africa) 1989].

\section{Education, Employment, and Residence}

Fertility is noted to be associated with some demographic and socio-economic variables. These variables are found to have depressant effects on fertility through proximate factors, which influence fertility positively or negatively. Some of the major background and proximate covariates of fertility include: education, health services, economic opportunities, infant and childhood mortality levels, availability and access to contraceptives, nutritional status and breastfeeding, amenorrhoeal variables, types of residence, marital status and duration of marriage, and abortion (refer to the Conceptual Frame Work, see Figure 1).

Rising levels of education result in lowering fertility rates. The exact linkages between these two variables have not been direct. Education is more likely to affect age at marriage since the typical school or college student is generally to postpone marriage and childbearing. Women's education is likely to rise age at marriage and in some countries reduce the probability of ever marrying. It should also be noted that education positively influences the knowledge, attitudes, and practice toward birth control 
mechanisms and enhances effective husband/wife communications (Lucas and Meyer 1994).

Education improves economic opportunities in the labour market by lowering their opportunity cost of childbearing, which is a major input of time into child care and rearing in illiterate societies. Raising the demand for child schooling prompts parents to reconsider the number of children they can afford. Also, an increase in female literacy will increase female economic participation.

Fertility is found to be highly correlated with female participation in the labour market. Several studies have shown that a new birth constrains the probability of wife's participation in the labour markets. According to Caldwell, education influences fertility by reducing the benefits from child's work and motivates the investment on children. Also it speeds the cultural change and increases the cost of children (Caldwell 1982). Lee and Bulatao (1983) also had hypothesised that fertility is inversely related to women's labour force participation, which is inconsonance with the 1980's findings in many Asian countries that the promotion of female employment was found to be a powerful tool for reducing fertility.

The employment opportunities in different economic institutions for families and the extent to which impersonal markets exit (for goods and services, credit, insurance, etc.) give rise to lowering the demand for children. Specific economic arrangements alter the significance of reproductive patterns of the socially defined needs over the life cycle (Lee and Bulatao 1983), and labour market opportunities in modern sector have proved to have depressant effects on the levels, patterns, and trends of fertility.

With respect to the influence of residence, Lucas and Meyer (1994) argued that rural population tends to stick to traditional values and norms of an ideal high family size. Children are favoured as social prestige for the extended family and contributors to the resources of the family. In contrast, the urban dwellers are better educated and have higher educational status than their rural counterparts, and their fertility levels, patterns, and trends are consistently lower than in the rural environment.

\section{Infant and Childhood Mortality}

The availability of health services in a country can have an impact on fertility. The health care systems affect fertility through its effects on mortality, morbidity, and fecundity. Family planning supply factors through delivery and legitimating fertility control services can influence fertility levels. The coverage of immunization programmes in most SSA countries has been increasing. Consequently, the survival probabilities of infants, children, and mothers have improved considerably. Thus, the replacement effect of fertility for high infant and childhood mortality may be anticipated to decline. But, the high potential of inertia in the age structure of many SSA countries suggests that fertility would still remain superior.

Lowering infant and childhood mortality and thus reducing the number of births is necessary to ensure survival of a desired number of children (replacement effect). In low developing societies, especially in SSA, children are viewed as social security, prestige, and economic assets. Children in many traditional societies make significant economic contributions to the households in the form of labour. Again, parents in these societies rely on children for care and economic support in old ages (Lee and Bulatao 1983).

In societies where infant mortality is very high, there is a tendency that parents may fear that some of their children could die and therefore try to ensure some survival by having a higher number of births. This argument implies that high fertility is partly explained by a response of a society with high infant mortality, which is termed as compensating/replacement effect.

When an infant survives, the birth interval on average is longer than when it dies. Moreover, the earlier the death takes place, the shorter the birth interval tends to be. Similarly, high child mortality 
rates may encourage families to have more children in response or replacement for high childhood mortality rates. At the same time, high fertility may increase childhood mortality through the effects of frequently and closely spaced pregnancies on the mother's capacity to bear healthy children, and large families can strain/drain household resources.

\section{Contraceptive Prevalence}

Different contraceptives have different effects on fertility, depending on the kind of the choice of contraception. Knowledge and use of contraception and attitudes toward contraception could equally well refer to birth control or family planning (Lucas and Meyer 1994). The relationship between women's schooling and contraceptive use depends on minimum threshold of the level of schooling, women's educational status, and availability of and access to family planning services. Women's schooling has statistically significantly positive relationship with contraceptive use in Botswana, Senegal, Zambia, and Zimbabwe.

\section{Nutritional Status and Breastfeeding}

There is considerable evidence to show that breastfeeding suppresses fertility by delaying the return of ovulation for the following birth. The biological explanation to the depressant effects on next ovulation is that the function of certain hormones for ovulation is diverted to the production of breast milk (Lee and Bulatao 1983). Consequently, women use intensive breastfeeding to postpone conception and subsequent births.

\section{Food and Nutrition}

The level of availability and utilization of food and nutrition (proteins, calories, and vitamins) has some influences on fertility performance. It is well known that birth rates would substantially be reduced during food shortages and prolonged famine. It was referred in a study of nutrition-fertility linkages by Bongaarts and Delgado (1977) to the fact that nutrition affects fertility level through various proximate determinants such as menarche, postpartum amenorrhoea, and fecundity. Their study showed that age at menarche can have depressant or positive effects on fertility and nutrition itself can influence the initiation of menses to be earlier or later.

A study on the effects of nutritional status on reproduction by Bongaarts and Delgado (1977) indicated that a decrease in nutritional status has a consistent, positive, and generally significant influence on the postpartum amenorrhoeal interval. The same study by Tyson, Friesen, and Anderson (1972) also indicated that undernutrition reduces the flow and availability of breast milk of lactating mothers, and if infants depend on the mother's milk for nourishment, then the decrease in milk flow may be compensated by the increase in the intensity and duration of suckling by the infants, thereby prolonging amenorrhoeal period and acting as anti-ovulationary process.

But, the fact is that the dominance of agrarian societies in the SSA countries, experiencing high fertility, could not follow the argument of the relationship between lack of food to supplement infant's diet and its effect on fertility via suppressing the menses. There could be other superior physiological factors which could compensate the depressant effects of food deficiency on menses, thereby affecting the reproductive performance of women.

Against the preceding background and proximate variables of fertility, the study investigates the strength of these factors in influencing fertility levels across the SSA countries.

\section{METHODOLOGY}

\section{Conceptual Framework}

The general theoretical framework of fertility covariates is depicted in Figure 1 below, which manifests the general guidelines for our analysis. 


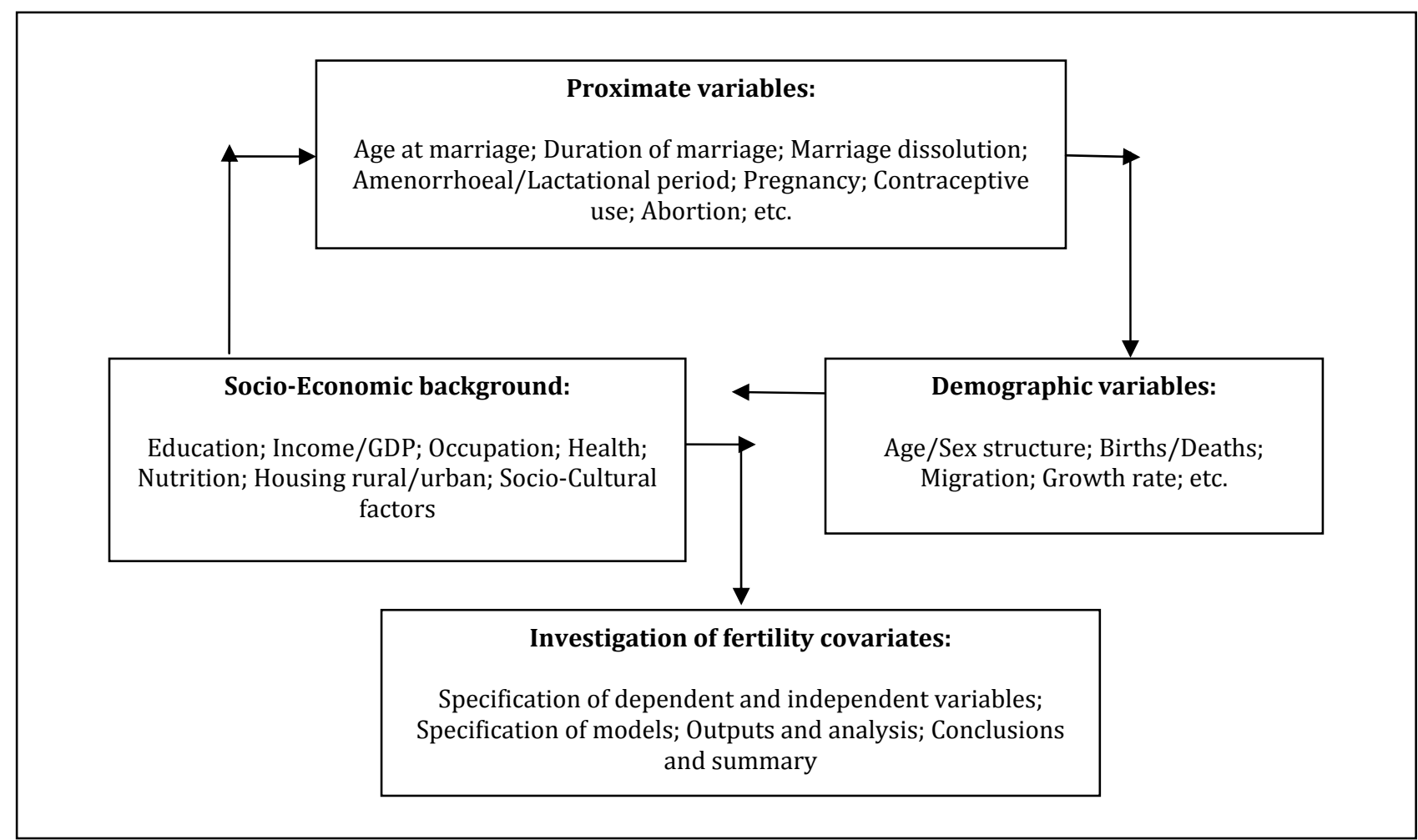

Figure 1. General Conceptual Framework Showing the Interrelationship Between Population, Socio-Economic and Proximate Variables With Fertility Outcome.

This figure conceptualises the theoretical structure of the study on fertility covariates/correlates. It depicts the general paths of influences among the socio-economic, proximate, and demographic variables and singles out fertility from the general frame to show their influences on fertility. As shown in the figure, the socio-economic background variables affect the proximate variables, which in turn implicitly influence the fertility status in the demographic box. For example, education rises age at marriage and facilitates for the knowledge, changes in attitudes, and use of contraceptives, which influence fertility performance. Similar cyclical relationships among the socio-economic, proximate, and demographic groups can be stated to show their fertility influences.

\section{Data Sources and Setting}

Data for each country are compiled mostly from the
UNDP 2001 and 2002 Reports. There are some missing information in the reports for some countries. The gaps are filled by supplementing some variables from the 1997-2001 UNDP (United Nations Development Program) Reports. The internet is also used whenever information is not found in all the reports. However, two countries, Liberia and Sao Tome/Principe are removed from the list, for we were encountered by many missing values. The total number of SSA countries covered in this study is 42 with a total of nine variables.

Data are then entered into a computer and analysed using Microsoft Excel and Statistical Package for Social Science (SPSS). List of the variables which is thought to be fertility determinants with corresponding coded schemes is defined as follows:

Total fertility rate as dependent variable $(\mathrm{Y})$

(1) GDP per capita in US $\$\left(\mathrm{X}_{1}\right)$; 
(2) $\%$ of female adult literacy rate $\left(X_{2}\right)$;

(3) Infant mortality rate $\left(X_{3}\right)$;

(4) $\%$ of contraceptive prevalence rate $\left(\mathrm{X}_{4}\right)$;

(5) \% of women breastfeeding up to six months $\left(\mathrm{X}_{5}\right)$;

(6) $\%$ of population with access to health services $\left(\mathrm{X}_{6}\right)$;

(7) $\%$ of undernourished people $\left(\mathrm{X}_{7}\right)$;

(8) $\%$ of urban population $\left(\mathrm{X}_{8}\right)$.

\section{Analytical Techniques}

The main statistical methods which are applied in this paper are descriptive statistics, correlation matrix, and multiple regression.

(1) Descriptive statistics. Some commonly used central tendency measures are applied. If $\mathrm{X}_{1}, \mathrm{X}_{2}$, $X_{3} \ldots X_{n}$ are independent variables and $Y_{1}, Y_{2}, Y_{3} \ldots$ $Y_{n}$ are the dependent variables, the overall mean (TFR) and the standard deviations are computed using the following formulae:

$$
\begin{aligned}
\text { mean of } \mathrm{X}_{\mathrm{i}}{ }^{\prime} \mathrm{s}= & \bar{X}=\frac{1}{n} \sum_{i=1}^{n} X_{\mathrm{i}} ; \text { standard deviation }= \\
& \sqrt{\frac{1}{n}} \sum_{i=1}^{n}\left(X_{i}-\bar{X}\right)^{2}
\end{aligned}
$$

mean of $\mathrm{Y}_{\mathrm{i}}{ }^{\prime} \mathrm{s}=\bar{Y}=\frac{1}{n} \sum \mathrm{Y}_{\mathrm{i}}$; standard deviation $=$

$$
\sqrt{\frac{1}{n}} \sum_{i=1}^{n}\left(Y_{i}-\bar{Y}\right)^{2}
$$

The median values can also be calculated from the given frequency distributions of the observations of dependent and independent variables.

(2) Correlation matrix. The correlation matrix is a measure of the linear relationship among the independent variables themselves (see Table 1), relating positively or negatively to one another, reflecting multi-collinearity (Christensen 1996). The degree of the relationship is measured by a parameter, called correlation coefficient, which is labelled as " $r$ ".
If we assume $X_{i}$ 's as independent variables and $Y_{i}$ 's as dependent variables, then $r$ can be computed using the following formula:

$$
\begin{gathered}
\mathrm{r}=\frac{\operatorname{Cov}(X, Y)}{\sqrt{\operatorname{Var}(X)} \sqrt{\operatorname{Var}(Y)}}= \\
\frac{\frac{1}{n} \sum_{i=1}^{n}\left(X_{i}-\bar{X}\right)\left(Y_{i}-\bar{Y}\right)}{\sqrt{\frac{1}{n}} \sum_{i=1}^{n}\left(X_{i}-\bar{X}\right)^{2} \sqrt{\frac{1}{n} \sum_{i=1}^{n}\left(Y_{i}-\bar{Y}\right)^{2}}}
\end{gathered}
$$

The correlation coefficient " $\mathrm{r}$ " determines the strength of the linear relationship between the two variables, $\mathrm{X}$ and $\mathrm{Y}$. If $\mathrm{r}=+1$ or $\mathrm{r}=-1$, there is a perfect positive and negative correlation between the two variables, but $r=0$, showing no linear relationship. The correlation matrix model then investigates the correlations among the independent variables $X_{i}$ 's on one hand and the Y dependent variable with each of the independent variable on the other hand. And the statistical summaries are exhibited in a tabular form (see Table 1), showing the interrelationship among the independent variables and partial correlation of the dependent variables with each of the independent variables.

(3) Multiple regression. In this model, the TFR (Y) is considered as a dependent variable and certain selected background and proximate variables $\left(\mathrm{X}_{\mathrm{i}}{ }^{\prime} \mathrm{s}\right)$ are independent variables. Thus, the functional relationship between the dependent and independent variables is presented as follows: If we let " $\mathrm{X}_{\mathrm{i}}$ ' " represent all the socio-economic and demographic variables plus any proximate variables of interest and " $Y$ " be measurable fertility indicator, then fertility " $Y$ ", as dependent variable, can be expressed as a linear additive combination (function) of the independent/explanatory variable " $X$ ". The regression equation is then expressed as:

$$
\mathrm{Y}=\mathrm{F}(\mathrm{X}) \Rightarrow \mathrm{Y}=\alpha+\sum \beta_{\mathrm{i}} \mathrm{X}_{\mathrm{i}}+\epsilon
$$

where $\mathrm{i}=1,2,3, \ldots \mathrm{n} ; \beta^{\prime} \mathrm{s}=$ coefficients of determination and $\alpha=$ marginal value and $\epsilon=$ error terms. 
In explicit terms:

$$
\begin{gathered}
\mathrm{Y}=\alpha+\sum \beta_{\mathrm{i}} \mathrm{X}_{\mathrm{i}} \Rightarrow \\
\mathrm{Y}=\alpha+\beta_{1} \mathrm{X}_{1}+\beta_{2} \mathrm{X}_{2}+\beta_{3} \mathrm{X}_{3}+\ldots+\beta_{\mathrm{n}} \mathrm{X}_{\mathrm{n}}+\epsilon
\end{gathered}
$$

The parameters $\beta_{\mathrm{i}}$ 's measure the change in the mean value of $\mathrm{Y}$ to a unit (positive/negative) increase or decrease in the value of $\mathrm{X}_{\mathrm{i}}$ 's when all other independent variables are held constant. Furthermore, the strength of the linear relationship is measured by the coefficient of determination $\mathrm{R}^{2}$, which measures the proportion of variation in the dependent variable that is explained by the independent variables entered in the model. The $\mathrm{R}^{2}$ value always lies between 0 and 1 , where $R^{2}$ close to 1 implies that the independent variables perfectly explain the variations in the dependent variable of interest. If $\mathrm{R}^{2}$ is closer to 0 , which implies that a large proportion of the variation in $\mathrm{Y}$ is unexplained by the independent variables which entered in the model. This means that a large proportion in the variation is explained by independent variables which were not included in the model. Thus, the unexplained proportion is $1-\mathrm{R}^{2}$.

\section{ANALYSIS OF RESULTS}

\section{Level of Parity (Children Ever Born-CEB)}

Parity is the mean number of children ever born by each woman in her life time. Appendix-A presents the fertility trends by countries over the years 1970-2002. This annex shows that there appears some slight decrease in fertility in some countries. According to Van de Walle and Foster (1990), there was little evidence of a sustained fertility decline in SSA. Exceptions are countries such as Botswana, Zimbabwe, and South Africa and the small islands where family planning programs are having some impact (Lucas and Meyer 1994). For example, Cape Verde had the highest fertility decline of about $53 \%$, followed by South Africa with 52\%.

In contrast, three countries experienced an increase instead. They include Angola, Equatorial
Guinea, and Zaire. From the previous information, we could see that these countries had infant mortality rate as high as 100 per 1,000 live births, and this could be one possible reason for reporting an increase in their fertility. Countries which did not show any significant change in their fertility over the periods include Burundi, Uganda, Sierra Leone, Congo, Chad, and Guinea Bissau. Most of these countries were recently characterised by civil wars.

However, the picture can tell that SSA countries were characterised by high levels of fertility in the period of early 1970s, and the majority of countries experienced a slightly decline in the early 2000 s. The overall pattern and trends showed that there was a decline in fertility for each country as compared to the current situations in all the countries.

\section{Outputs of Correlation Matrix Application}

Data input for this model is shown in Appendix-A and the outputs are summarized in Table 1 which simply shows the multicollinear correlation among the independent variables themselves, showing either positively or inversely correlated with one another at .01 or .05 significant levels.

\section{Multiple Regression Analysis}

Data input for the model is presented in Appendix-B and the outputs of the multiple regression model are summarized in Table 2. The $\beta$-coefficients of the independent variables confirm the results in Table 2, except with per capita GDP $\left(\mathrm{X}_{2}\right)$ which showed positive as against inverse relationship in the correlation matrix. Also, the positive relationship of female education in Table 2 has now been reversed, showing a negative relation with fertility, which is still consistent with household micro-level analysis.

The layout of the combined linear relationship between the dependent and independent variables can, therefore, be expressed as follows:

$\mathrm{TFR}=5.949+.0027 \mathrm{X}_{1}-.9569 \mathrm{X}_{2}+.7764 \mathrm{X}_{3}-$ $3.3290 \mathrm{X}_{4}+.2720 \mathrm{X}_{5}-.7460 \mathrm{X}_{6}+1.1452 \mathrm{X}_{7}-1.1218 \mathrm{X}_{8}$ 
Table 1. Results of Correlation Matrix Model

\begin{tabular}{|c|c|c|c|c|c|c|c|c|}
\hline $\mathrm{X}_{\mathrm{i}}^{\prime} \mathrm{S}$ & $\mathrm{X}_{1}$ & $\mathrm{X}_{2}$ & $\mathrm{X}_{3}$ & $\mathrm{X}_{4}$ & $\mathrm{X}_{5}$ & $\mathrm{X}_{6}$ & $\mathrm{X}_{7}$ & $\mathrm{X}_{8}$ \\
\hline \multirow[t]{2}{*}{$\mathrm{X}_{1}$} & 1.000 & & & & & & & \\
\hline & . & & & & & & & \\
\hline \multirow[t]{2}{*}{$\mathrm{X}_{2}$} & $-.622^{* *}$ & 1.000 & & & & & & \\
\hline & $(.000)$ & . & & & & & & \\
\hline \multirow[t]{2}{*}{$\mathrm{X}_{3}$} & $-.697^{* *}$ & $.568^{* *}$ & 1.000 & & & & & \\
\hline & $(.000)$ & $(.000)$ & . & & & & & \\
\hline \multirow[t]{2}{*}{$\mathrm{X}_{4}$} & $.809^{* *}$ & $-.585^{* *}$ & $-.618^{* *}$ & 1.000 & & & & \\
\hline & $(.000)$ & $(.000)$ & $(.000)$ & . & & & & \\
\hline \multirow[t]{2}{*}{$\mathrm{X}_{5}$} & $-.824^{* *}$ & $.699^{* *}$ & $.708^{* *}$ & $-.793^{* *}$ & 1.000 & & & \\
\hline & $(.000)$ & $(.000)$ & $(.000)$ & $(.000)$ & . & & & \\
\hline \multirow[t]{2}{*}{$\mathrm{X}_{6}$} & $.431^{* *}$ & $-.618^{* *}$ & -.212 & $.360^{*}$ & $-.494^{* *}$ & 1.000 & & \\
\hline & $(.004)$ & $(.000)$ & $(.178)$ & $(.019)$ & $(.001)$ & . & & \\
\hline \multirow[t]{2}{*}{$\mathrm{X}_{7}$} & $-.606^{* *}$ & $.484^{* *}$ & $.564^{* *}$ & $-.633^{* *}$ & $.589^{* *}$ & $-.357^{*}$ & 1.000 & \\
\hline & $(.000)$ & $(.001)$ & $(.000)$ & $(.000)$ & $(.000)$ & $(.020)$ & . & \\
\hline \multirow[t]{2}{*}{$\mathrm{X}_{8}$} & $-.527^{* *}$ & $.492^{* *}$ & $.369^{*}$ & $-.426^{* *}$ & $.428^{* *}$ & $-.279^{*}$ & $-.421^{* *}$ & 1.000 \\
\hline & $(.000)$ & $(.001)$ & $(.016)$ & $(.005)$ & $(.005)$ & $(.073)$ & $(.136)$ & . \\
\hline
\end{tabular}

Notes: ${ }^{* *}$ Correlation is significant at the .01 level (2-tailed); ${ }^{*}$ Correlation is significant at the .05 level (2-tailed).

Table 2. The Regression Model Output

\begin{tabular}{lllll}
\hline Variables & $\begin{array}{l}\text { Standardized } \\
\beta \text {-coefficients }\end{array}$ & $\begin{array}{l}\text { Standard } \\
\text { error }\end{array}$ & t-values & P-values \\
\hline Constant & 5.949 & 1.873 & 3.18 & .003 \\
$\mathrm{X}_{1}$ & .0027 & .0047 & .56 & .223 \\
$\mathrm{X}_{2}$ & -.9569 & .7705 & -1.24 & .223 \\
$\mathrm{X}_{3}$ & .7764 & .6713 & 1.16 & .256 \\
$\mathrm{X}_{4}$ & -3.2930 & 1.1335 & -2.47 & .019 \\
$\mathrm{X}_{5}$ & .2720 & 1.1602 & .17 & .866 \\
$\mathrm{X}_{6}$ & -.7460 & .6956 & -1.07 & .291 \\
$\mathrm{X}_{7}$ & 1.4520 & .8972 & 1.62 & .115 \\
$\mathrm{X}_{8}$ & -1.1218 & .8363 & -1.46 & .155 \\
\hline
\end{tabular}

Note: The $\beta$ s and standard errors are in $\%$.

Of all the independent variables in the regression model, the family planning services $\left(\mathrm{X}_{4}\right)$ appear to have considerable influences in fertility reduction at 5\% significant level, while others, though not significant, appear to contribute to the variations in fertility, positively or negatively in varying degrees.

On the basis of the fitted model, we can see that the average total fertility rate of the SSA countries is estimated to be about six children per woman in the absence of any interventions. As shown in Table 3, the relative influence of each independent variable on the fertility levels appears to operate positively or negatively. For example, one unit increase in the use of contraceptive prevalence would decrease fertility level by $3.3 \%$ and one unit increase in poverty level would increase fertility level by about $1.5 \%$. 
Table 3. Model Summary of Variabilty

\begin{tabular}{llll}
\hline $\mathrm{R}$ & $\mathrm{R}$-square & Adjusted R-square & Std. error \\
\hline Variations & .804 & .757 & .702 \\
\hline
\end{tabular}

Similarly, the relative influences of per capita GDP, female education, the level of infant mortality rate, breastfeeding for less than six months, the level of health services, and the degree of urbanization can be interpreted from the values of the positive or negative $\beta$-coefficients of the model.

\section{Model Summary}

The collective effects of the independent variables on fertility level are reflected by a parameter designated as $\mathrm{R}^{2}$, which is termed as the coefficient of determination and measures the percentage of the total variability in the dependent variable that is explained by the independent variables. If this number is large, it suggests a substantial predictive ability of the independent variables. In this model, the adjusted $\mathrm{R}^{2}=.757$ means that about .757 (i.e., $76 \%$ ) of total variability in fertility can be explained by the variables in the model (see Table 3).

However, 24\% were assumed to be explained by other independent variables which were not included in the regression model and these independent variables appeared to have substantial predictive power on fertility variations.

For a woman, to have a certain number of births, depends on other factors that determine her next conception. There are other non-measured variables that can directly or indirectly affect the woman's completed family size. Some of these variables include migration factors, type of marriages, and some other socio-cultural believes of different societies. In societies where there is the desire for sons, fertility would be high because many families would continue to have as many children until they have at least one son.

\section{CONCLUSIONS}

SSA is characterised by high fertility as compared to the Western countries and this is not because we want more children, but because of the prevailing backwardness in all walks of life unlike the situation in Western and other developed societies.

This paper dealt with some selected covariates of fertility in SSA countries. Accordingly, fertility is noted to vary with the status of some demographic and socio-economic variables. These variables appeared to have enhanced or depressant effects on fertility levels.

The main analytical models of the study included the correlation matrix and multiple regression techniques. Fertility as dependent variable is noted to be positively related to high infant mortality level, breastfeeding for less than six months, and poverty; whereas, those negatively related were income, female education, contraceptive prevalence level, access to health services, and level of urbanization.

Although each of these variables had relative contribution to mediate fertility levels in SSA, and collectively explained about $76 \%$ of the variations in fertility, their forces were not strong enough to bring about significant change, except contraceptive prevalence level which was found to have important effect on fertility reduction at $5 \%$ statistically significant level.

Thus, this could lead us to the conclusion that fertility levels, patterns, and trends in SSA countries have still been potentially high and the era of rapid population growth rate in the sub-continent has not been over and continues to have great hindrance to harmonious and sustainable development between population and resources for at least in the foreseeable future. 


\section{APPENDIX}

Appendix-A. Fertility Levels and Trends in Sub-Saharan African Countries

\begin{tabular}{|c|c|c|c|c|c|}
\hline Country & $\begin{array}{l}\text { Total } \\
\text { fertility } \\
\text { rate } \\
1970-1975\end{array}$ & $\begin{array}{l}\text { Total } \\
\text { fertility } \\
\text { rate } \\
2000-2002\end{array}$ & Country & $\begin{array}{l}\text { Total } \\
\text { fertility } \\
\text { rate } \\
1970-1975\end{array}$ & $\begin{array}{l}\text { Total } \\
\text { fertility } \\
\text { rate } \\
2000-2002\end{array}$ \\
\hline Angola & 6.6 & 7.2 & Madagascar & 6.6 & 5.7 \\
\hline Benin & 7.1 & 5.7 & Malawi & 7.4 & 6.1 \\
\hline Botswana & 6.7 & 3.7 & Mali & 7.1 & 7 \\
\hline Burkina Faso & 7.8 & 6.7 & Mauritania & 6.5 & 5.8 \\
\hline Burundi & 6.8 & 6.8 & Mauritius & 3.2 & 1.9 \\
\hline Cameroon & 6.3 & 4.6 & Mozambique & 6.6 & 5.6 \\
\hline Cape Verde & 7 & 3.3 & Namibia & 6.6 & 4.6 \\
\hline C.A.R & 5.7 & 4.9 & Niger & 8.1 & 8 \\
\hline Chad & 6.7 & 6.7 & Nigeria & 6.9 & 5.4 \\
\hline Comoros & 7.1 & 4.9 & Rwanda & 8.3 & 5.7 \\
\hline Congo & 6.3 & 6.3 & Senegal & 7 & 5 \\
\hline Cote d'Ivoire & 7.4 & 4.7 & Seychelles & 2.5 & 1.8 \\
\hline Equatorial & 5.7 & 5.9 & Sierra Leone & 6.5 & 6.5 \\
\hline Ethiopia & 6.8 & 6.1 & South Africa & 5.4 & 2.6 \\
\hline Gabon & 5.3 & 4 & Swaziland & 6.9 & 4.5 \\
\hline Gambia & 6.5 & 4.7 & Tanzania & 6.8 & 5.1 \\
\hline Ghana & 6.9 & 4.1 & Togo & 7.1 & 5.3 \\
\hline Guinea & 7 & 5.8 & Uganda & 7.1 & 7.1 \\
\hline Guinea Bissau & 7.1 & 7.1 & Zaire & 6.5 & 6.7 \\
\hline Kenya & 8.1 & 4 & Zambia & 7.8 & 5.6 \\
\hline Lesotho & 5.7 & 3.8 & Zimbabwe & 7.6 & 3.9 \\
\hline
\end{tabular}

Note: Source of data: Compiled from UNDP (United Nations Development Program) 1970/1975 and 2000/2002 files.

Appendix-B. Demographic and Socio-Economic Variables in Sub-Saharan Africa (UNDP 2000/2002)

\begin{tabular}{llllllllll}
\hline Country & $\begin{array}{l}\text { Total } \\
\text { fertility } \\
\text { rate }\end{array}$ & $\begin{array}{l}\text { GDP } \\
\text { per capita }\end{array}$ & $\begin{array}{l}\text { Female } \\
\text { literacy } \\
\text { rate } \\
(\%)\end{array}$ & $\begin{array}{l}\text { Infant } \\
\text { mortality } \\
\text { rate }\end{array}$ & $\begin{array}{l}\text { Birth } \\
\text { control } \\
(\%)\end{array}$ & $\begin{array}{l}\text { Women } \\
\text { breast } \\
\text { feeding } \\
(\%)\end{array}$ & $\begin{array}{l}\text { People } \\
\text { access to } \\
\text { health } \\
\text { services } \\
(\%)\end{array}$ & $\begin{array}{l}\text { Under- } \\
\text { nourished } \\
\text { people } \\
(\%)\end{array}$ & $\begin{array}{l}\text { Urban } \\
\text { people } \\
(\%)\end{array}$ \\
\hline Angola & 7.2 & 2,040 & 42 & 154 & 8 & 93 & 30 & 50 & 34.8 \\
Benin & 5.7 & 980 & 23.6 & 94 & 19 & 89 & 18 & 14 & 43 \\
Botswana & 3.7 & 7,820 & 79.8 & 80 & 40 & 90 & 89 & 25 & 49.4 \\
Burkina-F & 6.7 & 1,120 & 14.1 & 104 & 12 & 98 & 90 & 32 & 16.9 \\
Burundi & 6.8 & 690 & 40.4 & 114 & 9 & 92 & 80 & 69 & 9.3 \\
Cameroon & 4.6 & 1,680 & 69.5 & 96 & 19 & 95 & 70 & 29 & 49.6 \\
Cape Verde & 3.3 & 5,570 & 65.7 & 29 & 53 & 95 & 90 & 35 & 63.3 \\
C.A.R & 4.9 & 1,300 & 34.9 & 115 & 15 & 93 & 45 & 41 & 41.7 \\
Chad & 6.7 & 1,070 & 34 & 117 & 8 & 91 & 30 & 38 & 24.2 \\
Comoros & 4.9 & 1,870 & 48.7 & 59 & 21 & 87 & 82 & 35 & 33.8 \\
Congo & 6.3 & 970 & 74.4 & 81 & 20 & 89 & 70 & 32 & 66 \\
\hline
\end{tabular}


Appendix-B. Continued

\begin{tabular}{|c|c|c|c|c|c|c|c|c|c|}
\hline Country & $\begin{array}{l}\text { Total } \\
\text { fertility } \\
\text { rate }\end{array}$ & $\begin{array}{l}\text { GDP } \\
\text { per capita }\end{array}$ & $\begin{array}{l}\text { Female } \\
\text { literacy } \\
\text { rate } \\
(\%)\end{array}$ & $\begin{array}{l}\text { Infant } \\
\text { mortality } \\
\text { rate }\end{array}$ & $\begin{array}{l}\text { Birth } \\
\text { control } \\
(\%)\end{array}$ & $\begin{array}{l}\text { Women } \\
\text { breast } \\
\text { feeding } \\
(\%)\end{array}$ & $\begin{array}{l}\text { People } \\
\text { access to } \\
\text { health } \\
\text { services } \\
(\%)\end{array}$ & $\begin{array}{l}\text { Under- } \\
\text { nourished } \\
\text { people } \\
(\%)\end{array}$ & $\begin{array}{l}\text { Urban } \\
\text { people } \\
(\%)\end{array}$ \\
\hline Cote d'voire & 4.7 & 1,490 & 38.6 & 102 & 15 & 81 & 30 & 14 & 44 \\
\hline Equatorial & 5.9 & 15,073 & 74.4 & 101 & 20 & 75 & 75 & 25 & 49.2 \\
\hline Ethiopia & 6.1 & 810 & 30.9 & 116 & 8 & 96 & 46 & 44 & 15.9 \\
\hline Gabon & 4 & 5,990 & 71 & 60 & 33 & 81 & 90 & 8 & 82.1 \\
\hline Gambia & 4.7 & 2,050 & 29.4 & 91 & 10 & 76 & 93 & 16 & 31.2 \\
\hline Ghana & 4.1 & 2,250 & 62.9 & 57 & 22 & 92 & 60 & 10 & 36.4 \\
\hline Guinea & 5.8 & 1,960 & 41 & 109 & 6 & 70 & 80 & 29 & 27.9 \\
\hline Guinea-B & 7.1 & 970 & 23.3 & 130 & 8 & 100 & 40 & 39 & 32.3 \\
\hline Kenya & 4 & 980 & 76 & 78 & 39 & 92 & 77 & 44 & 34.3 \\
\hline Lesotho & 3.8 & 2,420 & 93.6 & 91 & 30 & 90 & 80 & 26 & 28.7 \\
\hline Madagascar & 5.7 & 830 & 59.7 & 84 & 19 & 95 & 65 & 40 & 30.1 \\
\hline Malawi & 6.1 & 570 & 46.5 & 114 & 31 & 82 & 80 & 76 & 15.1 \\
\hline Mali & 7 & 810 & 34.4 & 141 & 8 & 95 & 30 & 32 & 30.8 \\
\hline Mauritania & 5.8 & 1,990 & 30.1 & 120 & 8 & 82 & 63 & 12 & 59 \\
\hline Mauritius & 1.9 & 9,860 & 81.3 & 17 & 75 & 55 & 100 & 5 & 41.6 \\
\hline Mozambique & 5.6 & 1,140 & 28.7 & 125 & 6 & 93 & 39 & 55 & 33.2 \\
\hline Namibia & 4.6 & 7,120 & 81.2 & 55 & 29 & 86 & 62 & 9 & 34.1 \\
\hline Niger & 8 & 890 & 8.4 & 156 & 14 & 80 & 32 & 46 & 21 \\
\hline Nigeria & 5.4 & 850 & 55.7 & 110 & 15 & 95 & 64 & 8 & 44.8 \\
\hline Rwanda & 5.7 & 1,250 & 60.2 & 96 & 13 & 97 & 80 & 23 & 6.3 \\
\hline Senegal & 5 & 1,500 & 27.6 & 79 & 13 & 91 & 40 & 25 & 48.1 \\
\hline Seychelles & 1.8 & 17,030 & 91 & 13 & 83 & 55 & 99 & 0 & 64.5 \\
\hline Sierra Leone & 6.5 & 470 & 36 & 182 & 4 & 78 & 38 & 43 & 37.3 \\
\hline South Africa & 2.6 & 11,290 & 84.6 & 56 & 56 & 87 & 92 & 24 & 57.6 \\
\hline Swaziland & 4.5 & 4,330 & 78.6 & 106 & 21 & 87 & 55 & 12 & 26.7 \\
\hline Tanzania & 5.1 & 520 & 66.5 & 104 & 25 & 90 & 80 & 47 & 33.2 \\
\hline Togo & 5.3 & 1,650 & 42.5 & 79 & 24 & 87 & 61 & 18 & 33.9 \\
\hline Uganda & 7.1 & 1,490 & 56.8 & 79 & 23 & 88 & 49 & 21 & 14.5 \\
\hline Zaire & 6.7 & 680 & 50.2 & 129 & 8 & 99 & 26 & 32 & 29 \\
\hline Zambia & 5.6 & 780 & 71.5 & 112 & 25 & 99 & 75 & 50 & 39.8 \\
\hline Zimbabwe & 3.9 & 2,280 & 84.7 & 76 & 54 & 91 & 61 & 38 & 36 \\
\hline
\end{tabular}




\section{Limitations of the Study}

The study is limited by three major variables. Firstly, this fertility study is at macro-level, for it was difficult to get timely data at household/individual levels; secondly, the available data do not reflect the current demographic and socio-economic conditions of the countries; thirdly, the study covers only 42 SSA countries, omitting the five North African countries and five others within SSA.

\section{References}

Anderson, R. M., R. M. May, M. C. Boily, and J. T. Rowley. 1991. "The Spread of HIV-1 in Africa: Sexual Contact Patterns and the Predicted Demographic Impact of AIDS." Nature 352(6336):581-589.

Boem, J. T., A. J. Nunn, and J. A. Whitworth. 1998. "Mortality Impact of the AIDS Epidemic: Evidence From Community Studies in Less Developed Countries." AIDS 12(1):3-14.

Bongaarts, J. 1989. "A Model of the Spread of HIV Infection and the Demographic Impact of AIDS." Statistics in Medicine 8(1):103-120.

Bongaarts, J. and H. Delgado. 1977. "Effects of Nutritional Status on Fertility." International Union for the Scientific Study of Population (IUSSP). International Population Conference, Mexico.

Caldwell, J. 1982. Theory of Fertility Decline. London: Academic Press.

Christensen, R. 1996. Analysis of Variance, Design and Regression. London: Chapman \& Hall.

ECA (Economic Eommission for Africa). 1989. "The Impact of Maternal and Child Health and Family Planning (MCH) Programmes on Fertility, Infant and Childhood Mortality and Maternal Health.” Developments in Family Planning Policies and Programmes in Africa. Legon, Ghana, University of Ghana, Regional Institute for Population Studies (RIPS), pp. 257-287.
1995. "Statistical Compendium on Contraceptive Prevalence and Practice in ECA Member States." Addis Ababa, Ethiopia, United Nations Economic Commission for Africa.

Gaisie, S. K. 1996. "Demographic Transition: The Predicament of Sub-Saharan Africa." Health Transition Review 6:345-369.

Lee, R. D. and R. A. Bulatao. 1983. Determinants of Fertility in Developing Countries. New York: Academic Press.

Lucas, D. and P. Meyer. 1994. Beginning Population Studies. Canberra: Australian National University Press, National Centre for Development Studies.

Tyson, J. E., H. G. Friesen, and M. S. Anderson. 1972. "Human Lactational and Ovarian Response to Endogeneous Prolation Release." Science 177:800-897.

Van de Walle, E. and A. D. Foster. 1990. "Fertility Decline in Africa: Assessment and Prospects." World Bank Technical Paper No. 125, Africa Technical Department Series. Washington, D.C.: The World Bank.

World Population Data Sheet. 2013. Population Reference Bureau, USA.

Zaba, B. and S. Gregson. 1998. "Measuring the Impact of HIV on Fertility in Africa." AIDS 12(1):41-50.

\section{Bio}

Hadgu Bariagaber, Ph.D., associate professor, senior lecturer (expert in quantitative and qualitative data collection and analysis) in the Department of Population Studies, Faculty of Social Sciences, University of Botswana, Botswana; research fields: population and sustainable development, being engaged in wide range research activities dealing with population theories, demographic and epidemiological transition, HIV/AIDS, socio-economic correlates of fertility and mortality, historical perspectives of the reciprocal relationship between population and development, advanced demographic and mathematical models in demographic research analysis applying statistical models such as linear and multiple regression, multivariate data analysis. 